\title{
Como os estudantes em mobilidade ERASMUS na Universidade de Aveiro percebem as variedades do português?
}

\section{How do ERASMUS mobility students at the University of Aveiro perceive the varieties of portuguese?}

\section{¿Cómo los estudiantes de movilidad ERASMUS de la Universidad de Aveiro perciben las variedades del portugués?}

\author{
Juliana Bertucci Barbosa ${ }^{1}$ (iD http://orcid.org/0000-0002-1510-633X \\ Velúnia Tristão de Freitas² (iD https://orcid.org/0000-0003-1982-7852
}

\begin{abstract}
RESUMO: Os estudantes em mobilidade na Universidade de Aveiro cursam pelo menos uma disciplina de Português como Língua Estrangeira durante o período de intercâmbio. Mesmo que a variedade ensinada seja a variedade europeia, esses alunos têm contato com outras variedades do português. Este trabalho investigou quais são as atitudes e percepções linguísticas desses alunos em relação a variedade brasileira e europeia. Para que isso fosse possível, elaboramos um teste de atitude e percepção linguística, com base na teoria variacionista, e aplicamos através da plataforma Google Forms. Os níveis linguísticos mais suscetíveis à avaliação dos estudantes foram o fonológico, lexical e monitoramento estilístico (grau de formalidade). As expressões avaliativas associadas mais frequentemente à variedade brasileira foram "mais fácil", "mais clara" e "mais suave" e as expressões mais frequentemente associadas à variedade europeia foram "mais difícil", "menos clara" e "mais formal". Além disso, os estudantes expressaram consciência acerca da variedade linguística e não demonstraram atitudes e avaliações com preconceito linguístico.
\end{abstract}

PALAVRAS-CHAVE: Percepções linguísticas. Variedades do português. Português como Língua Estrangeira.

\footnotetext{
${ }^{1}$ Doutora em Linguística e Língua Portuguesa. Professora Associada da Universidade Federal do Triângulo Mineiro (UFTM), Campus de Uberaba. Programa de Pós-graduação Mestrado Profissional em Letras/UFTM. Programa de Pósgraduação em Linguística e Língua Portuguesa/UNESP-Araraquara. Grupo de Pesquisa em Estudos Variacionistas (GEVAR). E-mail: julianabertucci@gmail.com

2 Graduada em Letras Português e Inglês pela Universidade Federal do Triângulo Mineiro (UFTM), Campus de Uberaba. Membro do Grupo de Pesquisa em Estudos Variacionistas (GEVAR) da UFTM. E-mail: veluniatristao@hotmail.com
} 
ABSTRACT: The mobility students at the University of Aveiro attend at least one subject of Portuguese as a Foreign Language during the exchange period. Even though the variety taught is the European variety, these students have contact with other varieties of Portuguese. This work investigated what are the attitudes and linguistic perceptions of these students in relation to the Brazilian and European variety. To make this possible, we designed a test of attitude and linguistic perception, based on variationist theory, and applied it through the Google Forms platform. The linguistic levels most susceptible to the students' assessment were the phonological, lexical and stylistic monitoring (degree of formality). The evaluative expressions most frequently associated with the Brazilian variety were "easier", "clearer" and "softer" and the expressions most frequently associated with the European variety were "more difficult", "less clear" and "more formal". In addition, students expressed awareness of linguistic variety and did not demonstrate linguistically biased attitudes and assessments.

KEYWORDS: Linguistic perceptions. Varieties of Portuguese. Portuguese as a Foreign Language.

RESUMEN: Los estudiantes de movilidad de la Universidad de Aveiro han asistido pelo menos a una asignatura de portugués como lengua extranjera durante o período de intercambio. Aunque la variedad que se enseña es la europea, estos estudiantes tienen contacto con otras variedades de portugués. Este trabajo investigó cuáles son las actitudes y percepciones lingüísticas de estos estudiantes en relación a la variedad brasileña y europea. Para lo hacer posible, diseñamos una prueba de actitud y percepción lingüística, basada en la teoría variacionista, y la aplicamos a través de la plataforma Formularios de Google. Los niveles lingüísticos más susceptibles a la valoración de los estudiantes fueron el seguimiento fonológico, léxico y estilístico (grado de formalidad). Las expresiones de evaluación asociadas con mayor frecuencia a la variado brasileño fueron "más fáciles", "más claras" y "más suaves" y las expresiones más frecuentemente asociadas a la variado europeo fueron "difíciles", "menos más claras" y "más formales ". Además, los estudiantes expresaron conciencia de la variedad lingüística y no demostraron actitudes y evaluaciones lingüísticamente sesgadas.

PALABRAS CLAVE: Percepciones lingüísticas. Variedades de portugués. Portugués como lengua extranjera.

\section{Introdução ${ }^{3}$}

O presente trabalho tem como objetivo investigar as percepções e as atitudes linguísticas de discentes do Programa Erasmust, na Universidade de Aveiro (UA), em relação às variedades da língua portuguesa, principalmente, as do Português Europeu (PE) e Português Brasileiro (PB). O Erasmus - uma sigla para European Region Action Scheme for the Mobility of University Students ou, em português, Esquema de Ação Regional Europeia para a Mobilidade de Estudantes Universitários -, é um programa que apoia e facilita a mobilidade acadêmica de estudantes e de professores universitários em países da Europa. Foi criado em 1987, sendo remodelado no ano de 2014 (a União

\footnotetext{
${ }^{3}$ Fomento: CAPES (No do processo: 88887.125384/2016-00).

${ }^{4}$ Acrônimo, pois coincide com o nome em latim do filósofo, teólogo, e humanista Erasmo de Roterdão (1465-1536)
} 
Europeia juntou todos os programas de intercâmbio em um só, criando o Erasmus+). A partir de 2014, o programa continuou possibilitando a cooperação internacional, financiada pela Comissão Europeia, passando a ter como objetivos principais a facilidade da gestão dos programas de intercâmbios, o combate ao desemprego e a criação de mais oportunidades de formação e de aprendizado entre estudantes de diferentes países (UNIVERSIDADE DE AVEIRO, 2021).

Na Universidade de Aveiro (UA), os bolsistas do Erasmus são estudantes em mobilidade acadêmica, portanto, vindos de outras universidades, em sua maioria de outros países europeus, que estudam a língua portuguesa durante um semestre como disciplina obrigatória ou em cursos livres na UA, independentemente de qual curso estão matriculados na instituição. Obviamente, como a disciplina é ministrada na UA, a variedade que é ensinada a esses alunos é o Português Europeu (PE), entretanto, devido à presença de alunos brasileiros na Universidade - tanto intercambistas quanto em regime normal, e imigrantes brasileiros no país -, tais estudantes Erasmus passam a também ter contato com essa outra variedade do português e percebem diferenças entre o PE e o PB. Assim, considerando esse cenário multilíngue, foi possível o questionamento de como os estudantes do Erasmus na UA percebem as diferentes variedades e quais são as atitudes em relação a essas variedades do português.

Além disso, também é justificável um estudo que focalize as percepções e atitudes de tais estudantes de português como língua estrangeira/adicional (PLE/PLA), para que possamos pensar em como abordar, em sala de aula de PLE/PLA, as especificidades das variedades do português sem ocasionar preconceitos e ou estereótipos.

Para atingirmos nossos objetivos, neste artigo, inicialmente apresentamos algumas conceituações teóricas sobre o tema abordado, sobre a presença da língua portuguesa no mundo e seu ensino como língua estrangeira. Em seguida, apresentamos os procedimentos metodológicos e as análises dos dados. É importante mencionar que o interesse por essa pesquisa surgiu durante o desenvolvimento do projeto "O ensino de língua/literatura em português no Brasil e em Portugal: contribuições para formação inicial de professores da área de Letras", aprovado no edital do Programa de Licenciaturas Internacionais (PLI/CAPES) 5 .

\footnotetext{
${ }^{5}$ Em Portugal, mais especificamente, na cidade de Aveiro, onde fora realizado o intercâmbio acadêmico, há uma
} diversidade de alunos oriundos de países de línguas eslavas, neolatinas, germânicas, asiáticos, entre outras. Por isso, 


\section{Percepções e Atitudes Linguísticas: afinando conceitos}

Para o desenvolvimento desta pesquisa, inicialmente é necessário contextualizarmos, sucintamente, o que adotamos como concepções de percepções e atitudes linguísticas. Cabe mencionar que crenças, percepções e atitudes são elementos constitutivos da identidade linguística dos falantes, por isso é difícil defini-los separadamente. Na Psicologia Social, crenças são abstratas e impactam na forma como o indivíduo capta o mundo (o percebe) e como o avalia, por isso, se estudarmos as percepções e atitudes linguísticas, inferimos as suas crenças (BARBOSA; MARINE, 2019).

Oushiro (2015) define percepções linguísticas como inferências conscientes ou inconscientes que um falante pode fazer sobre outros falantes ao ouvi-los. Já a avaliação relaciona-se com o discurso metalinguístico desses falantes. Assim, esses conceitos são utilizados para investigar as relações que os falantes criam entre variações linguísticas e grupos sociais dos falantes.

Já atitude linguística, de acordo com Freire (2016, p. 57),

pode ser tomada como $o$ ato do que pensa e faz o falante com a língua em diferentes contextos da interação comunicativa, o que irá revelar que não só se usa a língua. Assim esta não é só instrumento de açãointeração, mas, sobretudo, o que o falante faz e diz algo com ela. E é, justamente, esse ato que se propõe como atitude linguística.

Ainda dentro da Psicologia Social, segundo Barbosa e Marine (2019), as percepções e atitudes são conceituadas como reações, positivas ou negativas, a algo ou alguém, e estão estruturadas em três dimensões: cognitiva (pensamentos e crenças), afetiva (sentimentos) e comportamental (uso). Como o falante acha que fala ou acha que deve falar (cognitivo) é a manifestação verbalizada, sem reações afetivas, acerca da sua crença sobre seus usos e sobre os padrões da comunidade. Como o falante julga aqueles que falam de determinado jeito (afetivo) é a manifestação de reações afetivas em relação ao objeto em questão.

$\mathrm{Na}$ Sociolinguística, para mensurar atitudes e percepções linguísticas, são utilizadas abordagens de forma direta (dimensão afetiva cognitiva), perguntando-se aos 
falantes o que pensam sobre determinado fato da língua ou, de forma indireta (dimensão afetiva), apresentando amostras escritas ou faladas de variedades de uma determinada língua e solicitando suas avaliações. Neste projeto, utilizaremos a forma direta e a indireta.

Alguns estudos já apontam as percepções e atitudes linguísticas de brasileiros, como Freitag et al. (2016), que analisaram as atitudes linguísticas em relação ao português brasileiro, considerando as percepções de estudantes universitários brasileiros do Sul e do Nordeste. Entretanto, segundo as autoras, além de caracterizá-los, é preciso "refletir sobre como as representações sobre a língua e variedades faladas produzem efeitos, também, sobre rótulos como "brasilidade", "regionalidade" linguística e "dialetos"'"' (FREITAG et al., 2016, p. 65). Os participantes dessa pesquisa avaliaram a língua utilizando expressões como "muito difícil" e "fantástica", por exemplo. Além disso, Freitag et al. (2016) verificaram apreciações valorativas sobre a percepção do contínuo de formalidade. Já na percepção de diferenças linguísticas em relação a outros falantes, os resultados demonstraram que os participantes mencionaram elementos como sotaque e gírias.

Outro trabalho recente é de Oushiro (2015), que investigou sobre a avaliação, produção e percepção linguística no português paulistano, tendo como objetivo principal analisar as relações entre a identidade social dos falantes e os significados sociais de usos linguísticos. Segundo esse estudo, a pronúncia do R como retroflexo foi avaliada negativamente em relação ao status do falante (classe social, nível de escolaridade e outros) e mais positivamente em relação à solidariedade e dinamismo (por exemplo, simplicidade e solidariedade).

Estudos de percepções e atitudes de falantes/aprendizes de português como língua não materna em relação às variedades do português dentro dessa perspectiva teórica da Sociolinguística da Percepção e da Psicologia Social ainda são escassos e carecem de mais investigações, justificando-se, assim, a necessidade de estudos como o desta pesquisa.

\section{Breve contextualização histórica da língua portuguesa no mundo}

Segundo Oliveira (2013), o interesse pela língua portuguesa vem aumentando no mundo, sendo ela uma das línguas de mais rápido crescimento neste momento histórico. 
Dentre os motivos, para tal autor, estão a presença da língua portuguesa nos ambientes virtuais e nos produtos da digitalização linguística e o aumento de mobilidades. No Brasil, podemos observar um sutil aumento de mobilidades principalmente acadêmicas e científicas, tanto de brasileiros para o estrangeiro (como, por exemplo, as que se iniciaram devido a fomentos como da CAPES em Programas de Cooperação Internacional como o extinto Ciências Sem Fronteiras ${ }^{6}$, o Programa de Licenciaturas Internacionais, o Programas de Cooperação Internacional de Formação de Professores da Educação Básica, entre outros) como de estrangeiros para o Brasil. Focalizando Portugal, de acordo com um artigo publicado na revista Exame, no ano letivo de 2016/2017, havia 4.901 estudantes brasileiros nas universidades portuguesas (TOTAL..., 2018). De acordo com Henriques (2019), o Serviço de Estrangeiros e Fronteiras divulgou que, em 2017, já havia mais de 85 mil brasileiros vivendo em Portugal.

Pode-se afirmar, portanto, que no século XXI a língua portuguesa alcançou um novo status de internacionalização, embora, no século anterior (o $\mathrm{XX}$ ), como já destacaram Oliveira (2013) e Oliveira e Jesus (2018), os países com língua portuguesa tenham enfrentado muitas crises. Um exemplo de momento crítico foi, por exemplo, o que ocorreu durante a Guerra Fria, em que países falantes do português enfrentaram diversos problemas econômicos e políticos. Ou ainda pode-se citar também: o fato de Portugal ter enfrentado 41 anos de regime salazarista; o Brasil ter passado pelo Estado Novo e pela ditadura militar e os Países Africanos de Língua Portuguesa (conhecidos como PALOP) terem lutado por sua independência.

Como pode ser observado, o século XX foi um período negativo para a tal idioma, já que seus falantes viveram em ambientes onde não havia (ou carecia) democracia, liberdade de expressão, perseguição a intelectuais e falta de acesso à educação. Especificamente no Brasil, como destaca Oliveira (2013), houve ainda, durante o período da ditadura Vargas, dentre outras medidas, a proibição de os imigrantes e seus descendentes falarem sua língua em público em todo território nacional, uma política de fechamento que impôs o monolinguismo.

Além disso, até o final do século $X X$, a língua portuguesa era bicêntrica, pois a normalização da língua era protagonizada por Brasil e Portugal. Entretanto, a partir do Acordo Ortográfico de 1990, o fortalecimento das vozes dos Países Africanos de Língua

${ }^{6}$ O Ciência Sem Fronteiras (CAPES) foi um programa de bolsas de estudo criado em julho de 2011 com o objetivo de incentivar a formação acadêmica no exterior. A iniciativa foi descontinuada por falta de verba (último edital em 2014). 
Oficial Portuguesa (PALOP) nas políticas linguísticas para o português e a criação da Comunidade de Países de Língua Portuguesa (CPLP), iniciou-se, como apontam Oliveira e Jesus (2018), o pluricentrismo ${ }^{7}$ da gestão da língua portuguesa. Nesse novo momento, a lusofonia se enriquece, iniciando uma mudança de cenário.

Ademais, em 1989, com a reunião contando com representantes do Brasil, de Portugal e dos PALOP, foi criado o Instituto Internacional de Língua Portuguesa (IILP). Isso teve grande relevância por beneficiar medidas em prol de uma comunidade geolinguística. Esse instituto foi responsável pela criação de um portal de materiais de ensino da língua que tem grande contribuição para o ensino pluricêntrico, o Portal do Professor de Português Língua Estrangeira/Língua Não Materna (PPPLE) ${ }^{8}$.

Outros fatos importantes para o reconhecimento da diversidade do português são, por exemplo, o reconhecimento (e criação) de duas Academias de Letras (do Brasil e de Portugal), o reconhecimento e usos de nomenclaturas como "Português do Brasil" (ou Português Brasileiro, PB), Português de Portugal (ou Europeu), Português Moçambicano, entre outros. Entretanto, não podemos esquecer que existe ainda uma busca por uma "norma convergente", por exemplo, através de acordos ortográficos e o Vocabulário Ortográfico Comum de Língua Portuguesa (VOC).

No Brasil, mais recentemente, temos ainda, como uma ação importante para a internacionalização do português, a criação do Idioma sem fronteiras (IsF) - atual Rede Andifes-IsF (desde 2019) -, um programa que busca promover ações em prol de uma política linguística para a internacionalização do Ensino Superior Brasileiro, valorizando a formação inicial e continuada de professores de línguas estrangeiras, incluindo de português para estrangeiros (PLE). Tal programa, embora já tenha passado por algumas reconfigurações, ainda está ativo em quase todas as universidades brasileiras, promovendo um amplo ensino não só Português como língua estrangeira, como também

\footnotetext{
7 Entendemos língua pluricêntrica assim como Mendes (2016, p. 294): "caracterizam-se por apresentar mais de um centro de referência, de onde emanam variadas normas linguísticas, nem sempre coincidentes do ponto de vista de seus usos. As normas variam internamente, porque apresentam diferenças dentro de uma mesma variedade de uso, e também variam externamente, como é o caso de normas que diferem entre países e regiões".

8 O PPPLE é, de acordo com Oliveira (2015), uma plataforma online que tem como objetivo principal oferecer à comunidade de professores e interessados, em geral, recursos para o ensino e a aprendizagem do português como língua estrangeira/ língua não materna. Foi concebido, desenvolvido, alimentado e tem sido gerido de forma multilateral, funcionando como instrumento de cooperação linguístico-cultural entre os Estados Membros. O PPPLE foi divulgado no II. Conferência Internacional sobre o Futuro do Português no Sistema Mundial, em Lisboa (outubro de 2013), já com Unidades Didáticas (UD) de Angola, Brasil, Moçambique e Portugal. As Unidades Didáticas (UD) têm estrutura comum, podem ser usadas e modificadas pelos professores, com retirada ou acréscimo de atividades, e são registradas com direito autoral de tipo creative commons.
} 
de Inglês, Espanhol, Francês, Italiano, Japonês, Alemão, Mandarim, entre outras línguas.

Além disso, no âmbito das políticas linguísticas do Brasil, temos ainda trocas produtivas e culturais, que devem ser mais incentivadas, com os países vizinhos da América do Sul por meio do ensino de espanhol no Brasil e do ensino do português nos países do MERCOSUL e UNASUL. Tais realizações são benéficas para a internacionalização do português, pois possibilitam

que falantes de outras línguas se apropriem (...) de uma cadeia mais longa de produtos, a que a língua dá acesso, criando elos mais profundos e, portanto, possibilitando trocas econômicas e culturais mais profundas e de médio e longo prazos (OLIVEIRA, 2013, p. 430)

Na busca pela internacionalização da língua portuguesa, é necessário que outros países de blocos como PALOP e CPLP participem ativamente de sua gestão e compartilhem a concepção de que ela é pluricêntrica. Pensando no ensino-aprendizagem de uma língua não materna, não podemos nos esquecer de que há um processo de contato com uma cultura e língua ainda não totalmente conhecidas por quem aprende. No caso da língua portuguesa, oficialmente presente em quatro continentes, aprender o idioma é uma oportunidade de transitar em muitos lugares e culturas do mundo. Porém, essa potencialidade só poderá ser aproveitada se a abordagem do professor de português for a de considerar a diversidade e as várias normas coexistentes, ou seja, a de considerar a língua portuguesa como pluricêntrica e pluricultural. A criação do Portal do Professor de Português Língua Estrangeira (PPLE) contribui para o ensino da língua numa perspectiva pluricêntrica, visto que esse portal reúne materiais de ensino elaborados em diversos países da CPLP. Isso faz com que o ensino tenha diversos centros de referência e culmina na valorização da diversidade cultural e linguística.

Assim, é nesse contexto de língua portuguesa como pluricêntrica que podemos questionar quais percepções os aprendizes de português como língua materna e estrangeira têm sobre o português e suas variedades. Por isso, considerando tais ponderações, torna-se pertinente um estudo que identifique as percepções e as avaliações linguísticas do ponto de vista dos que estão aprendendo português como língua estrangeira em um ambiente em que há convivência de mais de uma variedade da língua.

Silva (2012) investigou acerca das percepções dos alunos de português para falantes de outras línguas de um curso ministrado na Universidade Tecnológica Federal 
do Paraná, com o objetivo de identificar se eles apresentam atitudes preconceituosas e xenofóbicas sobre os brasileiros. A autora não só identificou qual era a percepção antes e depois do curso, mas também demonstrou que os momentos em que os aprendizes apresentam atitudes xenófobas são oportunidades para o professor adaptar seu trabalho e preparar os alunos, tornando a atitude negativa em oportunidade de levá-los a aprender construtivamente.

Considerando, portanto, questões como as descritas nesta seção, o presente trabalho tem como objetivo investigar quais as percepções e atitudes linguísticas dos estudantes de PLE/PLA e verificar como esses estudantes percebem as diferenças entre as variedades brasileiras e portuguesas. Além disso, buscamos identificar se os estudantes demonstram estereótipos, preconceito linguístico ou crenças negativas acerca das variedades da língua.

\section{Procedimentos Metodológicos}

Primeiramente, foi feita uma revisão bibliográfica sobre investigações acerca das atitudes e percepção linguística, como de Silva (2012), Oushiro (2015), Freitag et al. (2016), Barbosa e Marine (2019) e Santos (2019) e sobre a contextualização e ensino de língua portuguesa no mundo. Em seguida, elaboramos e aplicamos um teste de percepções e atitudes linguísticas a estudantes do Programa Erasmus da universidade de Aveiro, em mobilidade no período de 2019 e 2020, via plataforma Google Forms.

No questionário, os estudantes responderam perguntas de identificação socialacadêmica, questões abertas relacionadas à apreciação, e questões fechadas, em forma de escalas, relacionadas às atitudes linguísticas. O questionário foi apresentado em língua inglesa e língua portuguesa e aplicado duas vezes, primeiramente em uma versão "piloto" para apenas um aluno, para que pudéssemos verificar se havia clareza nas perguntas e necessidade de ajustes. A partir do feedback do teste piloto, realizamos pequenas alterações e realizamos a divulgação do teste nos grupos no Facebook e no Whatsapp do Programa Erasmus da Universidade de Aveiro.

\section{O teste de percepções e atitudes linguísticas}

O teste elaborado, com 26 itens, é composto de três partes:

(I) Parte I: com seis itens, visava conhecer os nossos informantes, suas 
nacionalidades, se aprenderam português antes da mobilidade, etc;

(II) Parte II: com cinco perguntas abertas, buscava coletar informações sobre o que os estudantes pensam sobre determinados fenômenos da língua e

(III) Parte III: com 13 itens, buscou-se coletar as percepções e atitudes dos participantes da pesquisa em relação as variedades do Português do Brasil (PB) e Europeu (Portugal) (PE). Nesta etapa, apresentamos fragmentos de áudio em língua portuguesa (do PE e do PB) e submetemos à apreciação dos estudantes.

Como podemos verificar acima, as partes II e III do teste, respectivamente, correspondem, a abordagens direta e indireta. A abordagem acontece de forma direta quando perguntamos aos estudantes o que pensam sobre determinados fenômenos da língua, o que permite investigar sobre a dimensão cognitiva; e abordagem indireta, quando os estudantes foram submetidos à apreciação de características linguísticas e, depois disso, atribuíram características psicossociais aos falantes, o que permitiu investigar a dimensão afetiva.

Na parte III, os participantes acessaram links, disponibilizados no Formulário do Google Forms, para ouvir quatro áudios. Esses áudios foram gravados por falantes nativos de português, com escolaridade nível superior (mesmo nível de escolaridade dos estrangeiros), sendo dois portugueses (um de Aveiro e outro de Viseu) e dois brasileiros (um de Uberaba e outro do Rio de Janeiro), com sistematizado no quadro 1 abaixo:

Quadro 1: Identificação das variedades do português dos áudios

\begin{tabular}{|c|c|c|}
\hline ÁUDIO & $\begin{array}{l}\text { AMOSTRA DA VARIEDADE } \\
\text { DO PORTUGUÊS }\end{array}$ & LINKS DE ACESSO AO ÁUDIO \\
\hline Áudio 1 (A1BR) & $\begin{array}{c}\text { Falante da variedade do Rio } \\
\text { de Janeiro (capital), }\end{array}$ & $\begin{array}{l}\frac{\text { https://drive.google.com/file/d/16 }}{\text { L66WmJM9xEnlsugNfdthon5wfTzI }} \\
\text { gjE/view?usp=sharing }\end{array}$ \\
\hline Áudio 2 (A1AV) & $\begin{array}{l}\text { Falante da variedade de } \\
\text { Aveiro (Portugal) }\end{array}$ & $\begin{array}{l}\frac{\text { https://drive.google.com/file/d/1 }}{\text { w3WQ2JdEFC FttFcRqGsLP9YjL8 }} \\
\text { FW1Ot/view?usp=sharing }\end{array}$ \\
\hline Áudio 3 (A1VS) & $\begin{array}{l}\text { Falante da variedade de Viseu } \\
\text { (Portugal) }\end{array}$ & $\frac{\text { https://drive.google.com/file/d/1L }}{\text { 4PNNzgQBPGZxIF574s3w5tVIcKM }}$ \\
\hline Áudio 4 (A1BR) & $\begin{array}{l}\text { Falante da variedade de } \\
\text { Uberaba (Brasil), }\end{array}$ & $\frac{\text { https://drive.google.com/file/d/1V }}{\text { VyllDYpuzmNYS8YUjNnAxCWAVx }}$ \\
\hline
\end{tabular}

Fonte: Elaborado pelas autoras

Nesses áudios, os falantes do português leram fragmentos literários. Após ouvirem-nos, os participantes responderam perguntas fechadas acerca de suas percepções sobre o que ouviram, por exemplo, com qual áudio se identificaram mais, 
qual era mais fácil de entender, entre outros. Cabe mencionar que os respondentes não foram informados sobre a nacionalidade dos falantes dos áudios.

As perguntas fechadas foram elaboradas em gradações em que o participante deveria selecionar entre 1-discordo e 5-concordo. Além disso, havia duas questões abertas optativas, em que o participante poderia escrever algum exemplo ou comentário que gostaria de compartilhar sobre os áudios e as perguntas.

Por fim, após divulgarmos o teste e coletarmos respostas, realizamos as seguintes etapas:

- análise qualitativa (de conteúdo) das respostas do teste9;

- $\quad$ seleção e quantificação das respostas;

- montagem de nuvens de palavras mais frequentes para análise;

- relação entre os resultados obtidos.

Para coleta dos dados, os participantes assinaram um termo de esclarecimento e consentimento on-line (via Google Forms), e, nas análises dos dados, foram identificados por meio de letras e números ( $\mathrm{P} 1, \mathrm{P} 2$, etc.) para que suas identidades ficassem no anonimato.

\section{Perfil dos informantes}

Como foi mencionado anteriormente, a primeira parte do teste tinha como objetivo conhecer o perfil dos participantes. O questionário foi respondido por sete estudantes universitários (um doutorando, três mestrandos, um graduando e dois não especificados), com faixa etária entre 20 e 34 anos.

Os estudantes são de diferentes nacionalidades: tres alemães, dois italianos, um húngaro e um jordano. Antes do intercâmbio, três participantes estudaram português. 0 participante P4 relatou que estudou português por um semestre, sem especificar como se deu esse aprendizado. $\mathrm{O}$ participante $\mathrm{P} 5$ afirmou ter estudado português durante dois anos na universidade. Já o participante P7 afirmou ter estudado esse idioma por dois

\footnotetext{
${ }^{9}$ Segundo Bardin (2016), a Análise de Conteúdo é uma técnica muito utilizada para análise em pesquisas qualitativa, em que se analisa a frequência de ocorrência de determinados assunto, termos, construções e referências em um dado texto, em nosso caso, nas respostas dos participantes da pesquisa (estrangeiros em Aveiro).
} 
anos e meio de modo autodidata antes do intercâmbio. O perfil geral dos participantes pode ser visualizado no Quadro 2 a seguir.

Quadro 2: Perfil dos informantes da pesquisa

\begin{tabular}{|c|c|c|c|c|}
\hline Participante & Nacionalidade & Idade & $\begin{array}{l}\text { Curso/Nível de } \\
\text { escolarização }\end{array}$ & Estudo prévio de português \\
\hline P1 & alemão & 26 & Mestrado & Não \\
\hline P2 & jordano & 34 & Doutorado & Não \\
\hline P3 & húngaro & 25 & Turismo & Não \\
\hline P4 & alemão & 27 & Mestrado & 1 semestre \\
\hline P5 & alemão & 23 & Graduação & $\begin{array}{c}2 \text { anos na universidade de } \\
\text { origem }\end{array}$ \\
\hline P6 & italiano & 27 & Mestrado & Não \\
\hline P7 & italiano & 20 & Graduado & $\begin{array}{c}2 \text { anos e meio de modo } \\
\text { autodidata }\end{array}$ \\
\hline
\end{tabular}

Fonte: Elaborado pelas autoras

Apenas um dos participantes optou por responder em português e os restantes responderam em inglês. Embora não seja a língua materna de nenhum dos participantes, as respostas em Língua Inglesa se devem, provavelmente, pelo fato de os alunos terem maior proficiência nesse idioma.

\section{Análises gerais do teste}

Na primeira etapa da análise das partes II e III do teste, inicialmente, buscamos verificar informações gerais dos informantes sobre percepções em relação às variedades do português e comparações com suas línguas maternas. Para isso, montamos uma nuvem de palavras (Figura 1, a seguir) utilizando a extensão Word Cloud para o Chrome a partir de palavras/expressões mais frequentes nas respostas abertas obtidas nas perguntas de 7 a 11, da segunda parte do teste, e das perguntas 13, 20 e 24 da terceira parte. Tais palavras/expressões indicaram, por exemplo, quais níveis linguísticos (fonológico, lexical, morfológico, etc) chamam mais atenção (são mais perceptíveis) dos aprendizes em relação às diferenças do PE e do PB. Cabe mencionar que excluímos palavras que não acrescentavam informações relevantes para o estudo.

A nuvem de palavra é organizada de modo que os termos que mais frequentes são apresentados em fontes maiores, vejamos: 
Figura 1: Nuvem de palavras (análise geral)

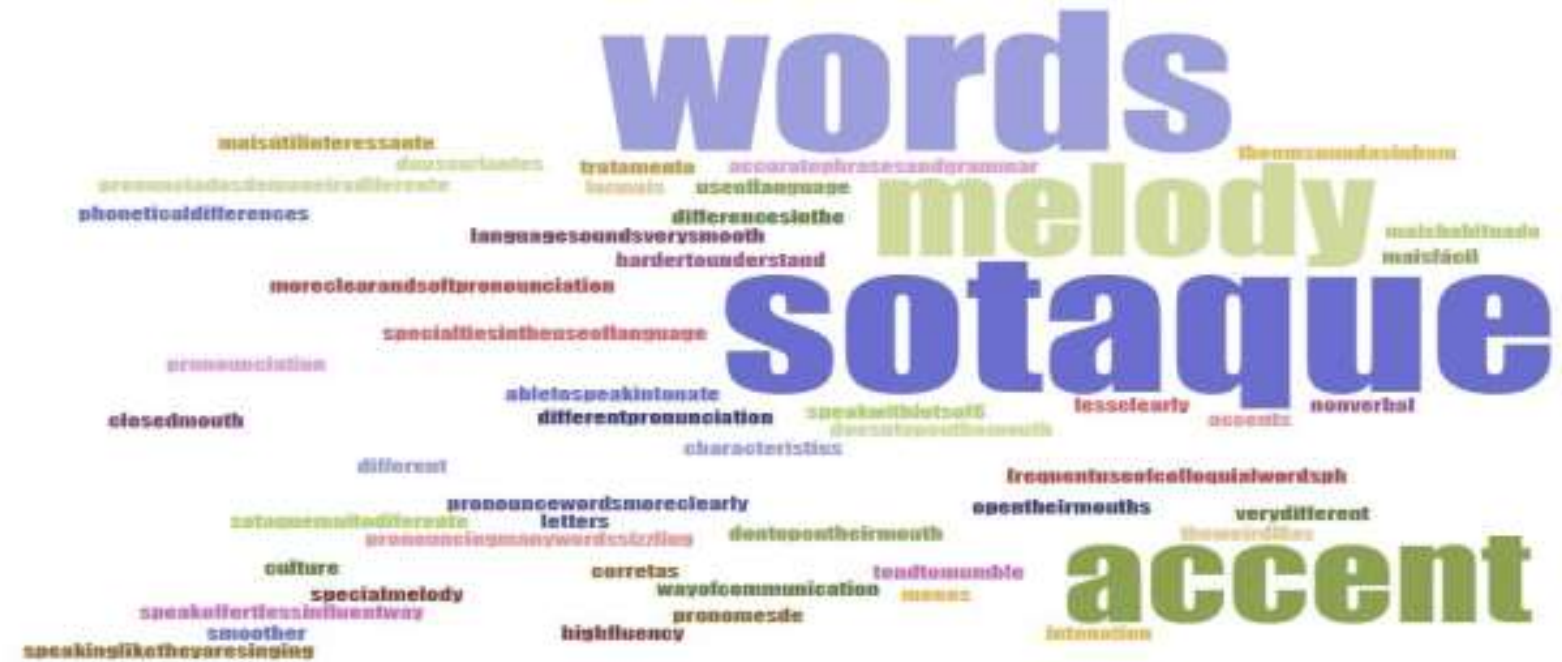

Fonte: Elaborado pelas autoras

Como podemos observar, a partir da Figura 1, é possível separar as percepções dos aprendizes de PLE do Erasmus em três categorias:

- as percepções relacionadas a aspectos prosódicos e fonológicos (quando mencionam sotaque, melodia, etc.),

- as percepções relacionadas a grau de dificuldade de aprendizagem (quando citam adjetivos tais como "mais claro, mais difícil e mais suave")

- as percepções associadas a monitoramento estilístico (quando citam "grau de formalidade", por exemplo).

Para prosseguirmos com as análises, considerando a nuvem de palavras elaborada, verificamos que as percepções relativas à língua e aos níveis linguísticos ficaram misturados, por isso, sentimos necessidade, também, de montar uma tabela com os adjetivos associados a cada variedade para análise.

Quadro 3 : Expressões avaliativas

\begin{tabular}{c|c}
\hline VARIEDADES DO PORTUGUÊS & ADJETIVOS/EXPRESSÕES AVALIATIVAS \\
\hline Português brasileiro (PB) & Mais claro, mais suave, mais fácil \\
\hline Português europeu (PE) & $\begin{array}{c}\text { Menos claro, mais difícil, menos fácil, mais } \\
\text { formal }\end{array}$ \\
\hline
\end{tabular}

Fonte: Elaborado pelas autoras

A partir dos dados do Quadro 3, podemos perceber que a maioria dos participantes caracteriza o Português Europeu como uma estrutura "mais difícil" e "mais formal". 
Em relação à parte II do teste, como já descrito, buscamos observar como os participantes percebem as variedades do português, de modo geral, sem escutar ou avaliar aúdios (como fizemos na parte III). Assim, na parte II, pela pergunta 7 questionou-se como eles identificam um falante de língua portuguesa ("Como você identifica um falante de português?") e, a partir das respostas dadas, verificamos que as características fonológicas e lexicais foram as mais salientes. Isso pode ser verificado nos fragmentos a seguir:

Fragmento 1: P1: "Due to the words and the melody of the language"

Fragmento 2: P4: "They dont open their mouth when they speak."

Fragmento 3: P6: "From the accent"

Já na pergunta de número 8 ("Você se identifica com uma região específica que tem português como língua oficial? Por quê?"), obtivemos respostas bem diferentes entre os informantes. A maioria dos informantes ( 4 de 7 ) respondeu que não se identifica com nenhuma região. Dois informantes responderam que se identificam com Aveiro e Portugal, devido ao contato com o país ou semelhança com a própria cultura. Esses resultados podem ser exemplificados pelos fragmentos a seguir:

Fragmento 4: P5: "I partly identify with the region around Aveiro, because I studied there and because this region has some specialties in the use of language which are different from other regions of Portugal."

Fragmento 5: P7: "Eu acho que me identifico mais com Portugal porque é o país lusófono que mais conheço e tem muitas semelhanças com o meu país."

Um informante afirmou que se identifica com o português falado no Brasil:

Fragmento 6: P1: "Brasil, because I love the culture, mood, music, food and landscapes"

Na pergunta 9 (Quais características te mostram que alguém é falante de português?), obtivemos respostas que confirmam o que foi dito sobre as respostas da pergunta 7, repetindo-se comentários acerca do nível fonológico ou exemplos relacionados a esse nível linguístico. Isso pode ser visto no fragmento abaixo: 
Fragmento 7: P5: "For example the 'em' sound as in bem."

Nessa pergunta, destacamos, também, o aparecimento de um estereótipo acerca dos falantes. Isso pode ser observado no seguinte fragmento:

Fragmento 8: P6: "They often smile and they are usually very kind."

Esse comentário trata-se de um estereótipo por conter uma generalização acerca dos falantes brasileiros, visto que não é possível afirmar ou confirmar que todos os falantes de português brasileiro são pessoas sorridentes ou gentis.

Na pergunta 10 (Você acha que portugueses e brasileiros falam diferente? Como?), os comentários acerca dos níveis linguísticos fonologia e léxico também foram predominantes, como se vê nos seguintes fragmentos: .

Fragmento 9: P1: "Yes, I do. Brazilians have a more clear and soft pronounciation while Portuguese speak less clearly, are pronouncing many words sizzling and it seems they speak more with a "closed" mouth."

Fragmento 10 P7: "Sim. O sotaque é muito diferente, as palavras que terminam com -te ou -de são pronunciadas de maneira diferente. Os pronomes de tratamento também são diferentes, e 'menos formais' no português brasileiro."

Por fim, na parte III do teste, como já descrito anteriormente, os participantes ouviram quatro gravações de áudio e foram confrontados com perguntas de apreciação e comparação entre os áudios/variedades. Consequentemente, a partir das percepções linguísticas dos participantes em relação às diferentes falas, pudemos inferir seus julgamentos e avaliações aos diferentes modos de falar. Como já mencionado, os respondentes não sabiam quais eram as nacionalidades (e, consequentemente, as variedades) dos falantes dos áudios gravados.

Na pergunta 12 (Você ouviu quatro áudios diferentes. Com qual deles você se identifica mais?), 71.4\% dos participantes (5 de 7), escolheram o áudio 2, gravado por um falante de origem de Aveiro, e $28.6 \%$ dos participantes (2 de 7) escolherem o áudio 4, gravado por um falante de origem de Uberaba. 0 fato de a maioria ter escolhido 0 áudio produzido por um aveirense já era esperando, visto que essa é a variedade com que os alunos tiveram mais contato. 
Por isso, para complementar os resultados obtidos a partir da pergunta 12 , elaboramos a número 13, "Por que você se identifica mais especificamente com esse falante?", que permitia respostas expositivas e subjetivas. Nessas respostas, os comentários feitos pelos participantes dão destaque, novamente, aos níveis fonológicos da língua, mas também associam características como clareza ou proximidade com o modo próprio de falar para justificar as escolhas. Esses resultados podem ser verificados a partir dos fragmentos a seguir.

Fragmento 11 P1: "Very clear and soft pronounciation, not a lot of sizzling"

Fragmento 12 P2: "It is more clear and easy. However, I believe that the 4th audio is good. Therefore, both second and 4th are clear."

Fragmento 13 P3: "It was clear"

Fragmento 14 P7: "Porque fala da maneira mais parecida a mim."

Tais resultados também mostram como o conceito de "clareza" é subjetivo, visto que está associado às percepções e atitudes linguísticas individuais e os participantes caracterizaram variedades diferentes como "mais clara". Para o participante P1, a variedade apresentada no áudio 4 é muito clara e, para os demais participantes, a variedade apresentada no áudio 2 é a mais clara. Além disso, o participante P7 confirma sua preferência pela variedade falada em Aveiro e menciona, mais uma vez, sua justificativa acerca da similaridade entre seu modo de falar e o dos portugueses.

$\mathrm{Na}$ sequência da pesquisa, os informantes deveriam selecionar, dentro de uma gradação de 1-discordo a 5-concordo, sua percepção linguística acerca das afirmações. De modo geral, houve uma grande oscilação nas respostas. Apesar disso, é possível perceber uma tendência mais favorável aos áudios 2 (falante aveirense) e 4 (falante uberabense).

Na pergunta 14 do teste ("O falante do áudio 1 fala português melhor do que 0 falante do áudio 2."), as respostas apresentam uma tendência maior para o "discordo" (4 de 7), como pode ser visto no Gráfico 1 : 
Gráfico 1 - 14 - "O falante do áudio 1 fala português melhor do que o falante do áudio 2?"

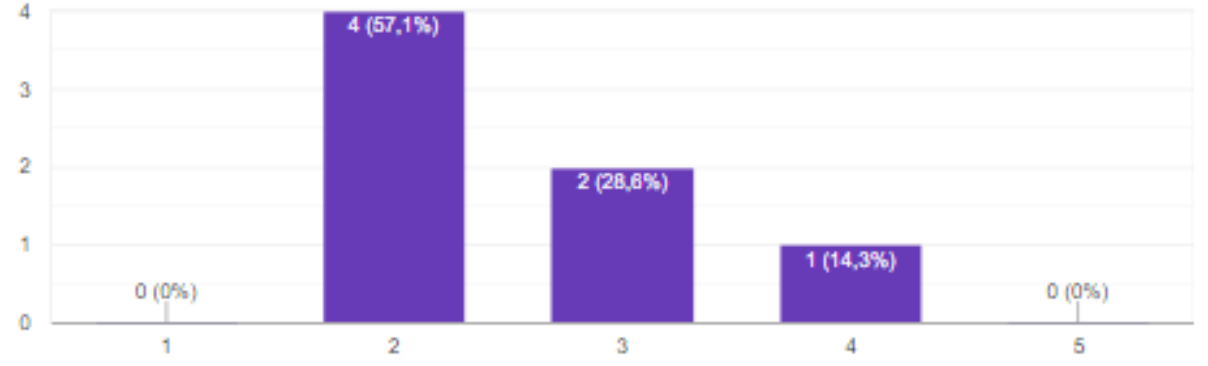

Fonte: Elaborado pelas autoras

Na pergunta de número 15 ("É mais fácil entender o falante do áudio 2 do que o falante do áudio 4."), as respostas se mostram equilibradas, visto que três participantes tendem para o "discordar" e três para o "concordar" com essa afirmação. Nessa afirmação, a resposta do participante P5 contradiz o que ele respondeu anteriormente na pergunta 12 (em que foram questionados: "Com qual deles [áudio] você se identifica mais?"), pois ele afirma entender melhor o áudio 4 (amostra do falar de Uberaba), mas na pergunta 12 selecionou o áudio 2 (amostra do falar de Aveiro) como o que se identifica mais.

Já o participante P2, que assinalou a opção neutra na gradação, tem uma resposta condizente com suas afirmações anteriores, visto que, na pergunta 12 , respondeu favoravelmente aos áudios 2 e 4 . As opções selecionadas pelos participantes podem ser visualizadas no gráfico a seguir:

Gráfico 2 - 15 - "É mais fácil entender o falante do áudio 2 do que o falante do áudio $4^{\prime \prime}$

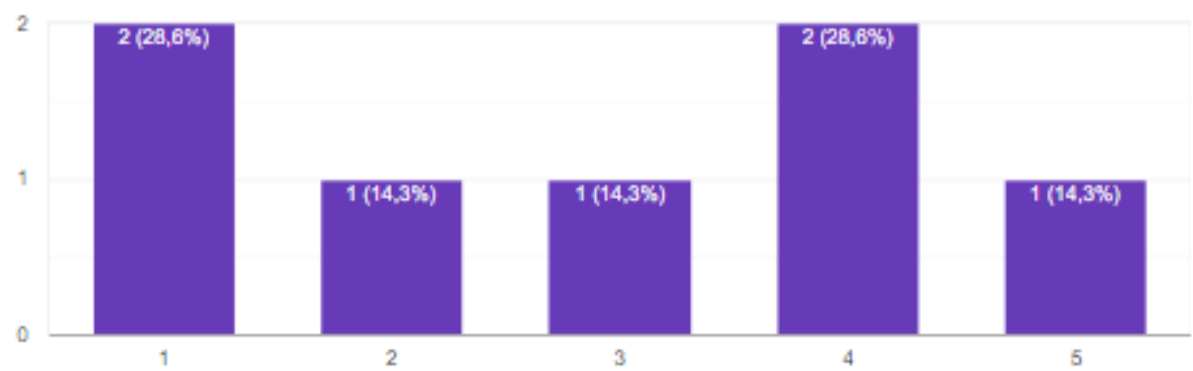

Fonte: Elaborado pelas autoras 
Na pergunta 16 ("O falante do áudio 4 fala português melhor do que o falante do áudio 3."), os participantes demonstraram uma tendência mais favorável à variedade brasileira apresentada no áudio 4 . Isso pode ser verificado no gráfico 3:

Gráfico 3 - 16 - "O falante do áudio 4 fala português melhor do que o falante do áudio 3"

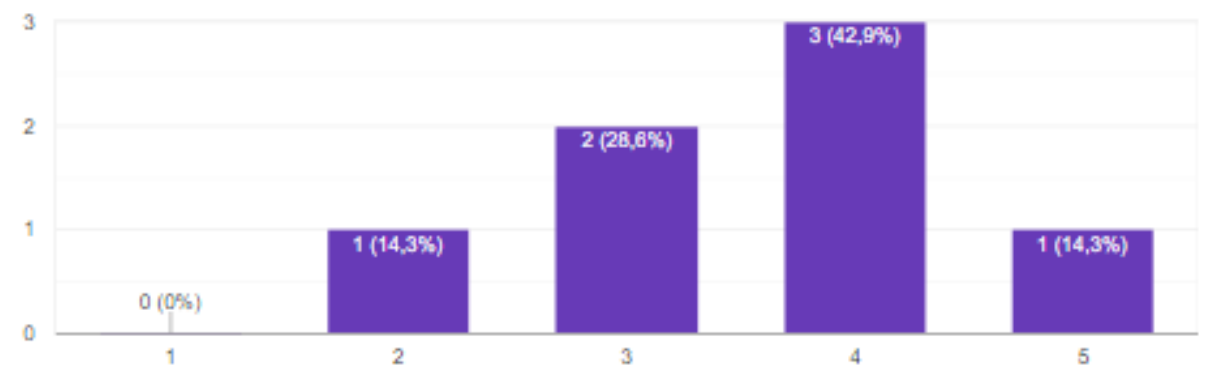

Fonte: Elaborado pelas autoras

Já a pergunta 17 ("O sotaque no áudio 2 é melhor do que o sotaque no áudio 1."), quatro participantes selecionaram pontos na gradação mais favorável ao áudio 2 . Isso confirma a tendência favorável à variedade de Aveiro demonstrada na pergunta 12 , como se vê no gráfico 4:

Gráfico 4-17 - O sotaque no áudio 2 é melhor do que o sotaque no áudio $1^{\prime \prime}$

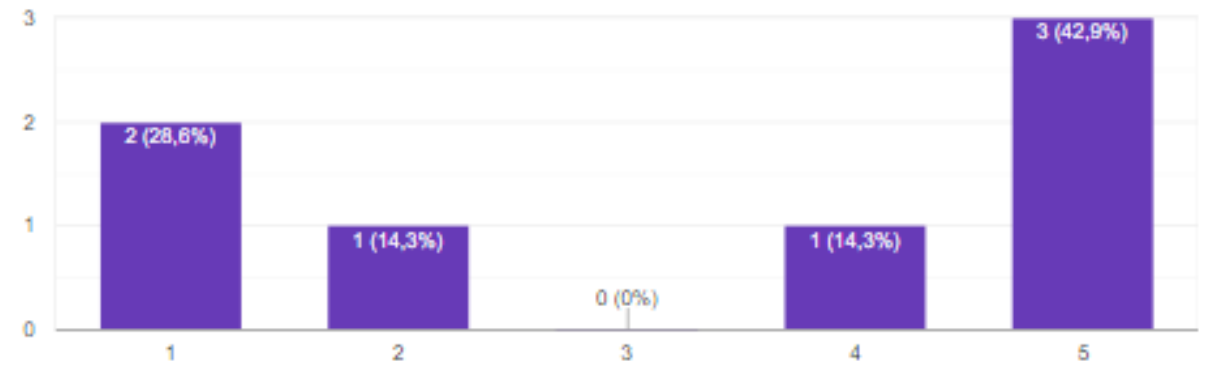

Fonte: Elaborado pelas autoras

Na pergunta 18 ("Os estudantes de português como segunda língua devem aprender a falar como o falante do áudio 2."), os participantes tiveram resposta predominantemente contrária a ensinar os estudantes de português a falarem como o falante do áudio 2. Isso pode ser verificado no gráfico abaixo: 
Gráfico 5 - 18 - "Os estudantes de português como segunda língua devem aprender a falar como o falante do áudio $2^{\prime \prime}$

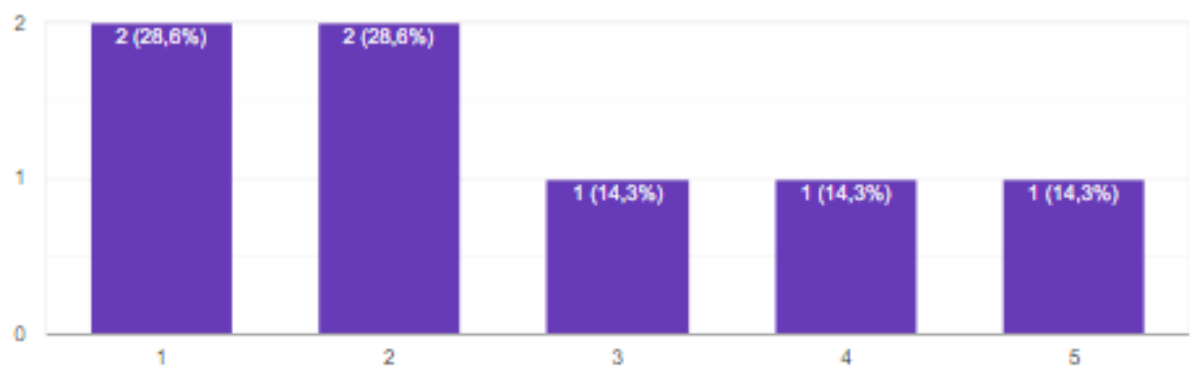

Fonte: Elaborado pelas autoras

Na pergunta 19 ("Os estudantes de português como segunda língua devem aprender a falar como o falante do áudio 4."), a maioria dos participantes (5 de 7) mostrou-se favorável a aprender a falar português como o falante do áudio 4 (de Uberaba). Um dado interessante sobre as respostas obtidas na pergunta 19 é o fato de que essas respostas se contradizem em relação ao que foi apresentado na pergunta 12, pois ao serem questionados, em 12 , sobre qual áudio se identificavam mais você, a maioria (71.4\% dos participantes) escolheu o áudio 2 (amostra do falar de Aveiro). Isso provavelmente se dá devido a diferença entre a variedade com a qual eles têm contato ao aprender português no curso (variedade de Aveiro) e o contato que têm com outras variedades em outros âmbitos sociais e suas atitudes linguísticas diante da variedade brasileira.

A partir da pergunta 21, questionamos sobre comparações entre as variedades do PB e PE. Na 21, ao questionarmos "É mais fácil entender os portugueses do que os brasileiros?", houve uma tendência maior para o "discordo", 4 dos 7 participantes marcaram os números mais próximos do "discordo" na gradação. Na pergunta 22 (Portugueses falam mais corretamente do que os brasileiros.), a maioria dos participantes, 4 de 7, marcou o neutro na gradação (gradação 3 da régua). Esse resultado se confirma nas perguntas abertas (números 20 e 24) dessa parte do teste, visto que os participantes demonstram uma consciência linguística e não afirmam que existe uma variedade caracterizada como "melhor" ou "pior".

Na pergunta 23 (Os estudantes devem aprender a falar como os portugueses), vemos uma tendência contrária a essa afirmação, visto que 4 dos 7 participantes 
marcaram números na gradação mais próximo de "discordo" e 2 se mantiveram neutros. Por fim, a pergunta 24 é uma pergunta aberta (Você gostaria de comentar algo sobre as perguntas de número 21 a 23?) para que os alunos pudessem detalhar ou justificar suas escolhas no teste de percepção. Os participantes responderam de maneira bem similar, como pode ser visto nos fragmentos abaixo:

Fragmento $14 \mathrm{P} 1$ : "Na minha opinião, só porque eles falam português diferente não significa que um deles fale melhor do que o outro como indicado nas perguntas 4 e $16^{\prime \prime}$.

Fragmento 15 P2: "Both of accents are OK but there is a lot of work need to be done in term of language course especially, the course that I obtained was not useful where there was a lack of materials and focus on reading rather than listening or writing"10

Fragmento 16 P4: "I don't think there is a right or wrong Portuguese regarding if it's spoken by Brazilians or Portuguese."11

Fragmento 17: P7: "Para mim é mais fácil perceber os portugueses do que os brasileiros porque estou mais habituado a este sotaque, mas as duas variantes são corretas e cada um aprende a que achar mais útil/interessante para ele/ela."

A partir desses fragmentos, podemos verificar, novamente, que os participantes apresentam consciência linguística sobre as variedades da língua.

\section{Conclusão}

Neste trabalho, motivado, especialmente, pela experiência de contato com os estudantes Erasmus durante o período de mobilidade acadêmica das pesquisadoras deste artigo na Universidade de Aveiro, em Portugal, investigamos as percepções e atitudes linguísticas que os estudantes de Português como Língua Estrangeira têm em relação, principalmente, às variedades do Português (PB e PE). Esse estudo não é exaustivo, mas aponta indícios do que o professor de PLE pode explorar em sala de aula, inclusive para desfazer mitos/visões equivocadas (como a de que o PE é mais difícil do que o PB).

De modo geral, conseguimos verificar que os aprendizes de PLE, estudantes em

\footnotetext{
10 P2: "Ambos os sotaques são OK, mas há muito trabalho que precisa ser feito em relação ao curso de língua especialmente, o curso que eu obtive não foi útil (porque) havia uma falta de materiais e foco em leitura em detrimento de escuta ou escrita."

11 "Eu não acho que existe um português certo ou errado considerando se é falado por brasileiros ou portugueses." (tradução nossa)
} 
Aveiro, têm consciência sociolinguística (percebem e avaliam) acerca das variedades brasileiras e europeias, entretanto, consideram uma variedade mais difícil em relação à outra e ainda atribuem à variedade brasileira um traço não linguístico e genérico: sorrir ao falar. Além disso, verificamos que os níveis fonológicos, prosódicos e lexicais são os mais suscetíveis às avaliações, ou seja, são os níveis da língua mais perceptíveis em detrimentos de outros não citados, como morfossintático, semântico ou pragmático. Esses são pontos (níveis linguísticos não citados) que podem, inclusive, ser explorados pelos professores de PLE/PLA em sala de aula, até mesmo comparando estruturas das variedades.

\section{Referências}

BARBOSA, Juliana Bertucci; MARINE, Talita De Cássia. Atitudes linguísticas de mestrandos das unidades do profletras da região do Triângulo Mineiro. In: MACHADO, Marcia dos Santos Machado; Wiedemer, Marcos Luiz (org.). Dimensões e experiências em Sociolinguística. São Paulo: Blucher, 2019. p. 269-293.

BARDIN, Laurence. Análise de conteúdo. Tradução de Luís Antero Reto, Augusto Pinheiro. 70. ed. São Paulo: Almedina Brasil, 2016.

FREIRE, Josenildo Barbosa. Variação, estilo, atitude e percepção linguística: o caso das laterais / $/$ / e /// no falar paraibano. 2016. Tese (Doutorado em Linguística) Universidade Federal da Paraíba, João Pessoa, 2016.

FREITAG, Raquel Meister Ko et al. Como os brasileiros acham que falam? Percepções sociolinguísticas de universitários do Sul e do Nordeste. Todas as Letras, São Paulo, v. 18, n. 2, p. 64-84, maio/ago. 2016.

HENRIQUES, Joana Gorjão. SEF confirma "aumento significativo" de brasileiros em Portugal. 2019. Disponível em:

https://www.publico.pt/2019/01/19/sociedade/noticia/aumento-significativo-brasileirossegundo-sef-1858491. Acesso em: 26 out. 2019.

MENDES, Edleise. Pluricentrismo linguístico, ensino e produção de materiais de Português LE no PPPLE. In: ALVAREZ, Maria Luisa Ortiz; GONÇALVES, Luis. (org.). $O$ Mundo do Português e o Português no Mundo Afora: especificidades, implicações e ações. Campinas: Pontes, 2016. p. 293-310.

OLIVEIRA, Gilvan Müller de; JESUS, Paula Clarice Santos Grazziotin de. Ensinando línguas em uma perspectiva pluricêntrica: o portal do professor de português língua estrangeira/língua não materna (pple). Domínios de Lingu@gem, Uberlândia. v. 12, n. 2, p. 1043-1070, abr./jun. 2018.

OLIVEIRA, Gilvan Müller de. O Instituto Internacional da Língua Portuguesa e a gestão 
multilateral da Língua Portuguesa no âmbito da CPLP. Revista Internacional de Linguística Iberoamericana, Madrid, v. 13, p. 19-34, 2015.

OLIVEIRA, Gilvan Müller de . Política linguística e internacionalização: a língua portuguesa no mundo globalizado do século XXI. Trabalhos em Linguística Aplicada, Campinas, v. 52, n. 2, p.409-433, jul./dez. 2013.

OUSHIRO, Lívia. Identidade na pluralidade: avaliação, produção e percepção linguística na cidade de São Paulo. 2015. Tese (Doutorado em Letras) -

Faculdade de Filosofia, Letras e Ciências Humanas, UNIVERSIDADE DE SÃO PAULO, sÃO Paulo, 2015.

SILVA, Gisele dos Santos da. Percepções de estrangeiros sobre a cultura brasileira durante o curso de português para falantes de outras línguas da UTFPR. 2012. Trabalho de Conclusão de Curso (Licenciatura em Letras Português-Inglês) - Universidade Tecnológica Federal do Paraná, Curitiba, 2012. Disponível em: https://repositorio.roca.utfpr.edu.br/jspui/bitstream/1/693/1/CT COLET 20121 04.pdf . Acesso em: 16 nov. 2019.

TOTAL de brasileiros em graduações em Portugal cresce 31\%. Exame, São Paulo, 10 maio /2018. Disponível em: https://exame.abril.com.br/carreira/total-de-brasileiros-emgraduacoes-em-portugal-cresce-31/. Acesso em: 26 out. 2019.

UNIVERSIDADE DE AVEIRO. Programa Erasmus+. Aveiro: Universidade de Aveiro, 2021. Disponível em: https://www.ua.pt/pt/erasmusplus/outgoing Acesso em: 20 jan. 2021.

Submetido em: 01 out. 2021. Aceito em: 19 out. 2021. 